\title{
Regional Tau Effects on Prospective Cognitive Change in Cognitively Normal Older Adults
}

\author{
${ }^{\circledR}$ Xi Chen, ${ }^{1,2}$ Kaitlin E. Cassady, ${ }^{1,2}{ }^{\circledR}$ Jenna N. Adams, ${ }^{2}$ Theresa M. Harrison, ${ }^{2}{ }^{\circledR}$ Suzanne L. Baker, ${ }^{1}$ and \\ ${ }^{-}$William J. Jagust ${ }^{1,2}$ \\ ${ }^{1}$ Molecular Biophysics and Integrated Bioimaging, Lawrence Berkeley National Laboratory, Berkeley, California 94720 , and ${ }^{2}$ Helen Wills \\ Neuroscience Institute, University of California Berkeley, Berkeley, California 94720
}

Studies suggest that tau deposition starts in the anterolateral entorhinal cortex (EC) with normal aging, and that the presence of $\boldsymbol{\beta}$-amyloid (A $\boldsymbol{\beta})$ facilitates its spread to neocortex, which may reflect the beginning of Alzheimer's disease (AD). Functional connectivity between the anterolateral EC and the anterior-temporal (AT) memory network appears to drive higher tau deposition in AT than in the posterior-medial (PM) memory network. Here, we investigated whether this differential vulnerability to tau deposition may predict different cognitive consequences of EC, AT, and PM tau. Using ${ }^{18} \mathrm{~F}$-flortaucipir (FTP) and ${ }^{11} \mathrm{C}$ Pittsburgh compound-B ( $\mathrm{PiB}$ ) positron emission tomography (PET) imaging, we measured tau and $\mathrm{A} \beta$ in 124 cognitively normal human older adults ( 74 females, 50 males) followed for an average of 2.8 years for prospective cognition. We found that higher FTP in all three regions was individually related to faster memory decline, and that the effects of AT and PM FTP, but not EC, were driven by A $\beta+$ individuals. Moreover, when we included all three FTP measures competitively in the same model, only AT FTP significantly predicted memory decline. Our data support a model whereby tau, facilitated by A $\beta$, transits from EC to cortical regions that are most closely associated with the anterolateral EC, which specifically affects memory in the initial stage of AD. Memory also appears to be affected by EC tau in the absence of A $\beta$, which may be less clinically consequential. These findings may provide clarification of differences between normal aging and $\mathrm{AD}$, and elucidate the transition between the two stages.

Key words: aging; Alzheimer’s disease; $\beta$-amyloid; memory; positron emission tomography; tau

Significance Statement

Tau and $\beta$-amyloid $(\mathrm{A} \beta)$ are hallmarks of Alzheimer's disease (AD) but are also found in cognitively normal people. It is unclear whether, and how, this early deposition of tau and $\mathrm{A} \beta$ may affect cognition in normal aging and the asymptomatic stage of $\mathrm{AD}$. We show that tau deposition in the entorhinal cortex (EC), which is common in advanced age, predicts memory decline in older adults independent of $\mathrm{A} \beta$, likely reflecting normal, age-related memory loss. In contrast, tau in anterior-temporal (AT) regions is most predictive of memory decline in $\mathrm{A} \beta+$ individuals. These data support the idea that tau preferentially spreads to specific cortical regions, likely through functional connections, which plays a primary role in memory decline in the early stage of $\mathrm{AD}$.

\section{Introduction}

The pathologic changes in Alzheimer's disease (AD), including $\beta$-amyloid $(\mathrm{A} \beta)$ and tau deposition, start decades before the symptoms (Price et al., 2009; Jack et al., 2013). With positron

Received Aug. 10, 2020; revised 0ct. 21, 2020; accepted Nov. 12, 2020.

Author contributions: X.C. and W.J.J. designed research; X.C., K.E.C., J.N.A., T.M.H., S.L.B., and W.J.J. performed research; X.C., K.E.C., J.N.A., T.M.H., and S.L.B. analyzed data; X.C. and W.J.J. wrote the paper.

This work was supported by National Institutes of Health Grants AG034570, AG062542, AG057107, and AG062090. Avid Radiopharmaceuticals enabled the use of the ${ }^{18} \mathrm{~F}$-Flortaucipir tracer, but did not provide direct funding and were not involved in data analysis or interpretation.

W.J.J. has served as a consultant for Biogen, Genentech, CuraSen, Grifols, and Bioclinica. All other authors declare no competing financial interests.

Correspondence should be addressed to Xi Chen at xi.chen@lbl.gov.

https://doi.org/10.1523/JNEUROSCI.2111-20.2020

Copyright $\odot 2021$ the authors emission tomography (PET) imaging, researchers can visualize the distribution of these two hallmark pathologies in the brain (Ossenkoppele et al., 2015; Johnson et al., 2016). Different from the diffuse accumulation of A $\beta$ (Nordberg, 2004), tau starts focally in the early stages of $\mathrm{AD}$, most commonly in the transentorhinal region, including the anterolateral entorhinal cortex (EC; Braak and Braak, 1992, 1995). This early EC tau increases with age and has been reported in individuals without $\mathrm{A} \beta$ pathology (Sonnen et al., 2011; Jack et al., 2019; Schöll et al., 2019). This $\mathrm{A} \beta$-independent tauopathy has recently been linked to agerelated memory decline in normal aging (Maass et al., 2018). On the other hand, high $\mathrm{A} \beta$ facilitates tau spreading outside EC, likely through neural connections (Pooler et al., 2015; Cho et al., 2016), which may signal the transition to AD (Braak and Braak, 1997). This tau deposition outside EC may be responsible for the 
initiation of clinically significant memory decline related to AD pathology.

In this study, we were interested in the cognitive consequences of tau deposition in cognitively normal individuals, especially in regions where we expect tau deposits early. One model for examining early stage tau deposition presupposes that tau spreads via patterns of neural connectivity, and is based on the organization of large-scale memory networks (Hoenig et al., 2018). This includes an anterior-temporal (AT) network comprising anterior and inferior temporal regions, specialized for object processing and item memory, and a posterior-medial (PM) network of medial parietal regions involved in context and spatial recognition (Ranganath and Ritchey, 2012). Recent evidence from our lab using the Berkeley Aging Cohort Study (BACS) suggests that tau preferentially deposits in the AT network, while $\mathrm{A} \beta$ preferentially deposits in the PM network (Maass et al., 2019). Preferential tau deposition in AT is likely because of its strong functional connection to EC, especially the anterolateral EC where tau initially deposits (Schröder et al., 2015; Adams et al., 2019). Meanwhile, the posteromedial subregion of EC also demonstrates connectivity to the neocortical regions of the PM network (Kerr et al., 2007; Schultz et al., 2012; Adams et al., 2019). While PM may also show tau deposition, it probably occurs later, since PM shows less tau burden in asymptomatic people compared with AT regions (Maass et al., 2019). This differential vulnerability to tau deposition allows us to examine the hypothesis that the earliest tau deposition outside $\mathrm{EC}$, within AT regions, is a better predictor of subsequent memory change than tau in EC or PM regions.

Few studies have examined this potential regional difference in tau effects on cognition, although there is abundant evidence that tau has an adverse effect on memory (Aschenbrenner et al., 2018; Sperling et al., 2019; Hanseeuw et al., 2019; Pontecorvo et al., 2019; Ziontz et al., 2019; Betthauser et al., 2020). However, the role of $\mathrm{A} \beta$ in this association, especially in normal aging, is still unclear (Maass et al., 2018; Sperling et al., 2019; Schöll and Maass, 2020).

Therefore, we aimed to investigate regional tau effects on memory in cognitively normal older people as well as the effects of $\mathrm{A} \beta$ by evaluating multiple regions susceptible to tau deposition. Because tau in EC is common in normal aging, we hypothesized that EC tau may predict memory change independent of $\mathrm{A} \beta$. We also hypothesized that tau in $\mathrm{AT}$ and $\mathrm{PM}$ regions would also affect memory change, but only in $\mathrm{A} \beta+$ individuals, since the spread of tau into neocortex seems to be $\mathrm{A} \beta$ dependent. Finally, while tau in EC, AT, and PM may each predict memory, we hypothesized that AT tau would have the strongest effect: as tau is more likely to spread from the anterolateral EC to AT regions first, $\mathrm{AT}$ tau may be most predictive of $\mathrm{AD}$-related decline in this early stage.

\section{Materials and Methods}

\section{Participants}

A total of 124 cognitively normal older individuals ( 74 females, 50 males) from BACS over age 65 were included in the study. All participants were cognitively normal enrolled, with Mini Mental State Examination (MMSE) score $\geq 25$, and remained normal throughout the study. Participants underwent structural 1.5T MRI, tau PET with ${ }^{18}$ F-Flortaucipir (FTP), A $\beta$ PET with ${ }^{11} \mathrm{C}$-Pittsburgh compound-B $(\mathrm{PiB})$, and a standard cognitive assessment that included measures of episodic memory, language, visuospatial ability, working memory and executive function. Most participants underwent repeated cognitive testing at one to two-year intervals, and 108 participants had at least two cognitive visits following their tau PET scan: 39 had two visits, 21 had three visits, 22 had four visits, 18 had five visits, and eight had six visits. All participants provided written, informed consent. The study was approved by the Institutional Review Board at the Lawrence Berkeley National Laboratory (LBNL) and the University of California, Berkeley.

\section{Cognitive assessment}

To examine prospective cognitive change, we only focused on cognitive assessments administered close to $(<180 \mathrm{~d})$ and after the tau PET scan. The time interval between cognitive assessment and tau PET scan was included as a covariate of no interest for all analyses. We used composite scores to examine cognitive performance over time. We calculated the composite score by first standardizing the raw measures based on the baseline mean and standard deviation. Then, for any task with multiple measures, we averaged measures of the same task to create a task score to minimize any task bias. Finally, we averaged across tasks of the same cognitive domain to form the composite score.

The primary cognitive domain studied was memory, which comprised five measures from three tasks, including short-delay free-recall and long-delay free-recall of the California Verbal Learning Test (Delis et al., 2000) and of Visual Reproduction (Wechsler, 1997), and total score of Logical Memory (Wechsler, 1997). We additionally explored the domain of executive function, using number correct in the Digit Symbol test (Smith, 1982), number correct in $60 \mathrm{~s}$ in the Stroop Interference Test (Stroop, 1938), and "trail B minus A" from the Trail Making Test (Reitan and Wolfson, 1985).

\section{MRI acquisition and processing}

Structural MRIs were acquired for PET preprocessing. Participants were scanned using a $1.5 \mathrm{~T}$ Siemens Magnetom Avanto scanner at LBNL. High-resolution anatomic images were collected with T1-weighted magnetization-prepared rapid gradient-echo (MPRAGE) images (1-mm isotropic voxels, $\mathrm{TR}=2110 \mathrm{~ms}, \mathrm{TE}=3.58 \mathrm{~ms}, \mathrm{FA}=15)$. All MPRAGE images were processed using FreeSurfer v5.3 (http://surfer.nmr.mgh. harvard.edu/). We derived regions of interest (ROIs) in participant's native space using the Desikan-Killiany atlas (Desikan et al., 2006). These segmentations were later used to extract regional uptake values, perform partial volume correction for the FTP data, and extract hippocampal volumetric, EC thickness, and white matter hypointensity measures used for supplementary analyses.

\section{PET acquisition and processing}

PET data acquisition was detailed previously (Ossenkoppele et al., 2016; Schöll et al., 2016; Adams et al., 2019). Both FTP and PiB were synthesized at the Biomedical Isotope Facility at LBNL and all PET imaging was conducted on a BIOGRAPH PET/CT scanner. For FTP scans, participants were first injected with $10 \mathrm{mCi}$ of tracer and data acquired from 80 to 100 min postinjection were used for analysis. CT scans collected before the start of emission acquisition were used for attenuation correction. We reconstructed the FTP-PET images using an ordered subset expectation maximization algorithm with scatter correction and smoothed with a 4-mm Gaussian kernel.

For FTP data processing, the mean tracer retention over $80-100 \mathrm{~min}$ postinjection was normalized by the mean tracer retention in the inferior cerebellar gray, as the reference region, to create FTP standardized uptake value ratio (SUVR) images. We performed partial volume correction (PVC) to account for partial volume effects related to atrophy and spillover signal, using the Rousset geometric transfer matrix method, as detailed previously (Rousset et al., 1998; Baker et al., 2017). Our primary interest was focused on three ROIs, composite AT and PM regions, and the EC. Subregions for AT and PM were selected a priori based on the literature on AT and PM networks (Ranganath and Ritchey, 2012; Inhoff and Ranganath, 2017; Maass et al., 2019). Specifically, AT FTP SUVR was calculated using a weighted average of inferior temporal cortex, amygdala, and fusiform cortex. PM FTP SUVR was calculated using a weighted average of parahippocampal gyrus, isthmus cingulate, and precuneus. EC FTP SUVR was based on the FreeSurfer parcellation of 
EC. The regional FTP SUVR of the left and right hemispheres were averaged to create the mean measure of regional FTP SUVR.

For PiB-PET imaging, participants were injected with $15 \mathrm{mCi}$ of $\mathrm{PiB}$ tracer, and $90 \mathrm{~min}$ of dynamic acquisition frames began immediately after the injection. A CT scan was obtained before the injection and used for attenuation correction. PiB-PET images were also reconstructed using an ordered subset expectation maximization algorithm with scatter correction and smoothed with a 4-mm Gaussian kernel.

For $\mathrm{PiB}$ data processing, distribution volume ratio (DVR) was generated with Logan graphical analysis (Logan et al., 1996; Price et al., 2005) on frames over 35-90 min postinjection, and normalized using the whole cerebellar gray as the reference region. Global PiB was calculated using multiple FreeSurfer ROIs across the cortex, as previously described (Mormino et al., 2012). We used the threshold of 1.065 of global DVR to define A $\beta$ positivity (Villeneuve et al., 2015). We did not perform PVC for $\mathrm{PiB}$ data, following the procedure used to define the $\mathrm{A} \beta$ positivity cutoffs in this cohort (Villeneuve et al., 2015). A $\beta$ is widely distributed in association cortex so PVC on PiB data offers little benefit in quantitation of tracer retention.

\section{Experimental design and statistical analyses}

Individual effect of tau in AT, PM, and EC on prospective memory change

To examine regional tau effects on memory change, three linear mixed models (LMMs) were conducted with time, regional FTP SUVR, and FTP SUVR $\times$ time interaction as predictors and the memory composite score as the outcome variable. Baseline age, sex, education (years), APOE status ( $\varepsilon 4$ carrier or not) and the time interval between baseline cognitive assessment and FTP PET were included as covariates, as well as the covariate $\times$ time interactions. Random effects included subject intercept and time slope. Another set of LMMs examined whether the tau effect was different in $\mathrm{A} \beta$ - and $\mathrm{A} \beta+$ groups, by additionally including $\mathrm{A} \beta$ positivity status and its interactions with time and tau (i.e., $\mathrm{A} \beta$ status $\times$ time, FTP SUVR $\times \mathrm{A} \beta$ status, and FTP SUVR $\times \mathrm{A} \beta$ status $\times$ time). We completed post hoc analyses examining the FTP SUVR level at which longitudinal memory started to decline. To do so, for AT and PM regions separately, we estimated the simple slopes of memory change at varying FTP SUVRs in A $\beta+$ individuals (Aiken et al., 1991) and identified the specific FTP SUVR value associated with the initiation of negative longitudinal memory change.

We then repeated the LMM analyses with continuous PiB DVR substituting for the dichotomized $\mathrm{A} \beta$ status, while controlling for the same covariates. This allowed us to confirm the reliability of our findings and explore the range of $\mathrm{A} \beta$ levels where a tau effect emerged: we estimated the conditional effect of FTP SUVR on memory change (slopes extracted using a simple LMM with only time as a predictor) at varying levels of $\mathrm{A} \beta$, and identified the specific global PiB DVR value at which FTP SUVR started to have a significant effect on memory change, using the JohnsonNeyman procedure (Johnson and Fay, 1950; Aiken et al., 1991).

Multiple regional tau measures simultaneously predicting prospective memory change

To test whether AT tau had the strongest effect on memory change among the three regions, using three LMMs, we examined the effects of (1) AT and EC FTP, (2) PM and EC FTP, and (3) AT and PM FTP on longitudinal memory, as well as their interactive effect with $\mathrm{A} \beta$ status. Finally, we included all three FTP measures simultaneously and explored their unique contributions when competitively examined in the same model. We included the same covariates as in previous analyses for these models.

All predictors were mean-centered to minimize multicollinearity. We also examined the variance inflation factor (VIF) for all models and found little evidence of problematic collinearity (James et al., 2013).

\section{Results}

\section{Demographics}

Participants' information at baseline is presented in Table 1. The within-subjects $t$ test revealed that FTP SUVR values were higher
Table 1. Participants' characteristics at baseline

\begin{tabular}{|c|c|c|c|c|}
\hline & $\begin{array}{l}\text { All } \\
\text { participants } \\
(N=124)\end{array}$ & $\begin{array}{l}\mathrm{A} \beta- \\
(N=72)\end{array}$ & $\begin{array}{l}A \beta+ \\
(N=51)\end{array}$ & $\begin{array}{l}\overline{A \beta-v S} \\
A \beta+ \\
p\end{array}$ \\
\hline Age & $77.3(5.9)$ & $77.3(6.9)$ & $77.3(4.2)$ & n.s. \\
\hline Sex: female $(N)^{4}$ & 74 (59.7\%) & 41 (56.9\%) & $32(62.7 \%)$ & n.s. \\
\hline Education (years) & $16.8(1.9)$ & $17.2(1.8)$ & $16.4(1.9)$ & 0.018 \\
\hline $\begin{array}{l}\text { Mean testing interval } \\
\text { (years) }\end{array}$ & $1.4(0.6)$ & $1.4(0.6)$ & $1.4(0.6)$ & n.s. \\
\hline $\begin{array}{l}\text { Cognitive follow-up } \\
\text { duration (years) }\end{array}$ & $2.8(1.2)$ & $2.8(1.3)$ & $2.8(1.2)$ & n.s. \\
\hline $\begin{array}{l}\text { Number of cognitive } \\
\text { assessments }\end{array}$ & $2.4(1.3)$ & $2.4(1.4)$ & $2.4(1.3)$ & n.s. \\
\hline Retained participants $(N)^{\mathrm{a}}$ & $15(87.9 \%)$ & $65(90.3 \%)$ & $43(84.3 \%)$ & n.s. \\
\hline $\begin{array}{l}\text { APOE status ( } N \text { of } \varepsilon 4 \\
\text { carriers) }{ }^{a, b}\end{array}$ & $31(25.6 \%)$ & $6(8.6 \%)$ & $25(50 \%)$ & $<0.001$ \\
\hline Global $A \beta(D V R)^{c}$ & $1.15(0.22)$ & $1.02(0.28)$ & $1.33(0.25)$ & $<0.001$ \\
\hline AT tau (SUVR) & $1.27(0.18)$ & $1.22(0.11)$ & $1.35(0.24)$ & $<0.001$ \\
\hline PM tau (SUVR) & $1.17(0.12)$ & $1.14(0.10)$ & $1.21(0.13)$ & 0.001 \\
\hline EC tau (SUVR) & $1.28(0.23)$ & $1.20(0.17)$ & $1.38(0.27)$ & $<0.001$ \\
\hline Hippocampal volume $\left(\mathrm{cm}^{3}\right)$ & $7.36(0.99)$ & $7.45(0.98)$ & $7.25(1.00)$ & n.s. \\
\hline Entorhinal thickness $(\mathrm{cm})$ & $3.36(0.37)$ & $3.35(0.35)$ & $3.36(0.40)$ & n.s. \\
\hline Baseline episodic memory & $0.01(0.77)$ & $0.10(0.77)$ & $-0.13(0.77)$ & n.s. \\
\hline Baseline executive function & $0.00(0.70)$ & $0.08(0.65)$ & $-0.12(0.77)$ & n.s. \\
\hline
\end{tabular}

n.s., not significant $(p>.05)$

${ }^{a}$ Sex is reported as number of female participants (\%); retained participants is reported as number of participants who remain participating in BACS (\%); APOE status is reported as number of $\varepsilon 4$ carriers (\%); other variables are continuous and reported as mean (SD).

${ }^{\mathrm{b}}$ Data were not available for three participants.

'Data were not available for one participant.

in AT $(p<0.001)$ and EC $(p<0.001)$, than the PM region, as expected. The independent sample $t$ test found no significant group difference in age, sex, testing interval, total duration of follow-up, number of longitudinal cognitive assessments, retention rate, hippocampal volume, EC thickness, baseline memory or executive function performance between $\mathrm{A} \beta-$ and $\mathrm{A} \beta+$ groups. However, the $\mathrm{A} \beta+$ group had fewer years of education $(p=0.018)$, higher percentage of APOE $\varepsilon 4$ carriers $(p<0.001$; in $\mathrm{A} \beta-, 14.3 \% \varepsilon 2 \varepsilon 3,77.1 \% \varepsilon 3 \varepsilon 3$ and $8.6 \%$ $\varepsilon 3 \varepsilon 4$; in $\mathrm{A} \beta+, 2 \% \varepsilon 2 \varepsilon 3,6 \% \varepsilon 2 \varepsilon 4,48 \% \varepsilon 3 \varepsilon 3$ and $44 \%$ $\varepsilon 3 \varepsilon 4$ ), and higher FTP SUVRs in all three tau ROIs (AT: $p<0.001$, PM: $p=0.001$, EC: $p<0.001)$.

\section{AT, PM, and EC tau individually predicts prospective memory change}

Using three LMMs, we examined the individual effect of FTP SUVR in AT, PM, and EC separately (Table 2, model 1; for statistics of all predictors, see Extended Data Tables 2-1, 2-2, $2-3)$. In all three regions, FTP showed a significant main effect on memory performance (AT: $p<0.001, \mathrm{PM}: p=0.007, \mathrm{EC}$ : $p<0.001$ ) and a significant FTP $\times$ time interaction (AT: $p<$ 0.001, PM: $p=0.014$, EC: $p=0.008$ ), suggesting that higher FTP SUVR was associated with greater memory decline and worse memory performance, as depicted in Figure 1.

\section{$\mathrm{A} \beta$ moderates $\mathrm{AT}$ and $\mathrm{PM}$ tau effect on prospective memory change}

We next examined whether the FTP effect differed in $\mathrm{A} \beta+$ and $\mathrm{A} \beta-$ individuals (Table 2, model 2; for statistics of all predictors, see Extended Data Tables 2-1, 2-2, 2-3). We found a significant three-way interaction of FTP $\times \mathrm{A} \beta$ status $\times$ time for both AT $(p=0.009)$ and PM $(p=0.023)$ models, such that higher FTP SUVR was more predictive of faster memory decline in the $\mathrm{A} \beta+$ group (Fig. 2). In contrast, we did not find any statistical difference in EC FTP effect between $\mathrm{A} \beta+$ and $\mathrm{A} \beta$ - individuals 
Table 2. Regression statistics for the effects of FTP, FTP $\times$ time, and FTP $\times$ $A \beta$ status $\times$ time in individual effect models

\begin{tabular}{|c|c|c|c|c|}
\hline & & AT & PM & $\mathrm{EC}$ \\
\hline \multicolumn{5}{|c|}{$\begin{array}{l}\text { Model 1: memory } \sim \text { sex }+ \text { age }+ \text { education }+ \text { APOE }+ \text { Cog-PET interval }+ \text { FTP }+ \\
\text { time }+ \text { age } \times \text { time }+ \text { sex } \times \text { time }+ \text { education } \times \text { time }+ \text { APOE } \times \text { time }+ \\
\text { Cog-PET interval } \times \text { time }+ \text { FTP } \times \text { time }+ \text { random slope }+ \text { random intercept }\end{array}$} \\
\hline \multirow[t]{2}{*}{ FTP } & $b$ (se) & $-1.51(0.36)$ & $-1.47(0.54)$ & $-1.57(0.26)$ \\
\hline & $p$ & $<0.001 * * *$ & $0.007 * *$ & $<0.001 * * *$ \\
\hline \multirow[t]{2}{*}{ FTP $\times$ time } & $b(\mathrm{se})$ & $-0.33(0.10)$ & $-0.28(0.11)$ & $-0.17(0.06)$ \\
\hline & $p$ & $<0.001 * * *$ & $0.014 *$ & $0.008 * *$ \\
\hline \multicolumn{5}{|c|}{$\begin{array}{l}\text { Model 2: memory } \sim \text { sex }+ \text { age }+ \text { education }+ \text { APOE }+ \text { Cog-PET interval }+ \text { FTP }+ \\
\text { A } \beta \text { status }+ \text { time }+ \text { FTP } \times \text { A } \beta \text { status }+ \text { age } \times \text { time }+ \text { sex } \times \text { time }+ \\
\text { education } \times \text { time }+ \text { APOE } \times \text { time }+ \text { Cog-PET interval } \times \text { time }+\mathrm{A} \beta \text { status } \times \\
\text { time }+ \text { FTP } \times \text { time }+ \text { FTP } \times \mathrm{A} \beta \text { status } \times \text { time }+ \text { random slope }+ \text { random } \\
\text { intercept }\end{array}$} \\
\hline \multirow[t]{2}{*}{ FTP } & $b(\mathrm{se})$ & $-1.49(0.48)$ & $-1.44(0.58)$ & $-1.50(0.31)$ \\
\hline & $p$ & $0.002 * *$ & $0.014 *$ & $<0.001 * * *$ \\
\hline \multirow[t]{2}{*}{ FTP $\times$ time } & $b(\mathrm{se})$ & $-0.20(0.11)$ & $-0.22(0.12)$ & $-0.13(0.07)$ \\
\hline & $p$ & $0.069 \dagger$ & $0.061 \dagger$ & $0.063 \dagger$ \\
\hline \multirow[t]{2}{*}{$\mathrm{FTP} \times \mathrm{A} \beta$ status $\times$ time } & $b(\mathrm{se})$ & $-0.55(0.21)$ & $-0.54(0.23)$ & $-0.22(0.14)$ \\
\hline & $p$ & $0.009 * *$ & $0.023 *$ & 0.12 \\
\hline
\end{tabular}

$* * * p<0.001, * * p<0.01, * p<0.05, \uparrow p<0.1$. For statistics of all predictors, see Extended Data Tables 2-1 (at), 2-2 (PM), and 2-3 (EC).

$(p=0.12)$. Based on the predicted memory trajectories, we were able to identify the AT and PM FTP SUVR value required to produce memory decline in the $\mathrm{A} \beta+$ group. For AT FTP, an SUVR $>1.29$ was associated with a negative longitudinal memory slope; and for PM FTP, the defining SUVR was 1.19. To further account for the effect of individual amyloid burden on these relationships, we used continuous PIB DVR values (see below, Defining values of PiB DVR for tau effects to emerge) in the models. For individuals with an average $\mathrm{A} \beta+$ group PIB DVR of 1.33 , equivalent to a value of 48 on the centiloid (CL) scale (Klunk et al., 2015), the AT FTP SUVR associated with a negative memory slope was 1.33, and for PM FTP, the value was 1.24.

We also note that the paradoxical increase in memory performance at FTP SUVR $=1$ for the $\mathrm{A} \beta+$ group in Figure 2 was a spurious effect. It occurred because model estimates are primarily driven by high FTP individuals because of very few individuals with FTP SUVR $=1$ in the $\mathrm{A} \beta+$ group (Fig. 3, histograms). This results in a skewed relationship in the low FTP range that is not representative of actual trajectories in those people (Extended Data Fig. 3-1).

Figure 3 further illustrates the individual data depicting the relationship between FTP and memory change (slopes extracted using a simple LMM with only time as a predictor), while controlling for age, sex, education, APOE status, and cog-PET interval. The visualization confirms the above finding that AT and PM FTP effect was only evident in $\mathrm{A} \beta+$ individuals, whereas the EC FTP effect was not statistically different in $\mathrm{A} \beta$ - and $\mathrm{A} \beta+$ individuals. The scatter plots and the histograms also reveal that high FTP SUVRs were primarily $\mathrm{A} \beta+$ cases and that the EC FTP effect was most different from AT and PM in the relatively low FTP range: a slight increase in EC FTP SUVR was associated with memory decline in both $\mathrm{A} \beta-$ and $\mathrm{A} \beta+$ individuals, while increased FTP in AT or PM regions was not related to memory decline in $\mathrm{A} \beta$ - individuals.

\section{Defining values of PiB DVR for tau effects to emerge}

The results were replicated when using PiB DVR as the continuous measure of $\mathrm{A} \beta$ : AT and PM FTP showed a significantly
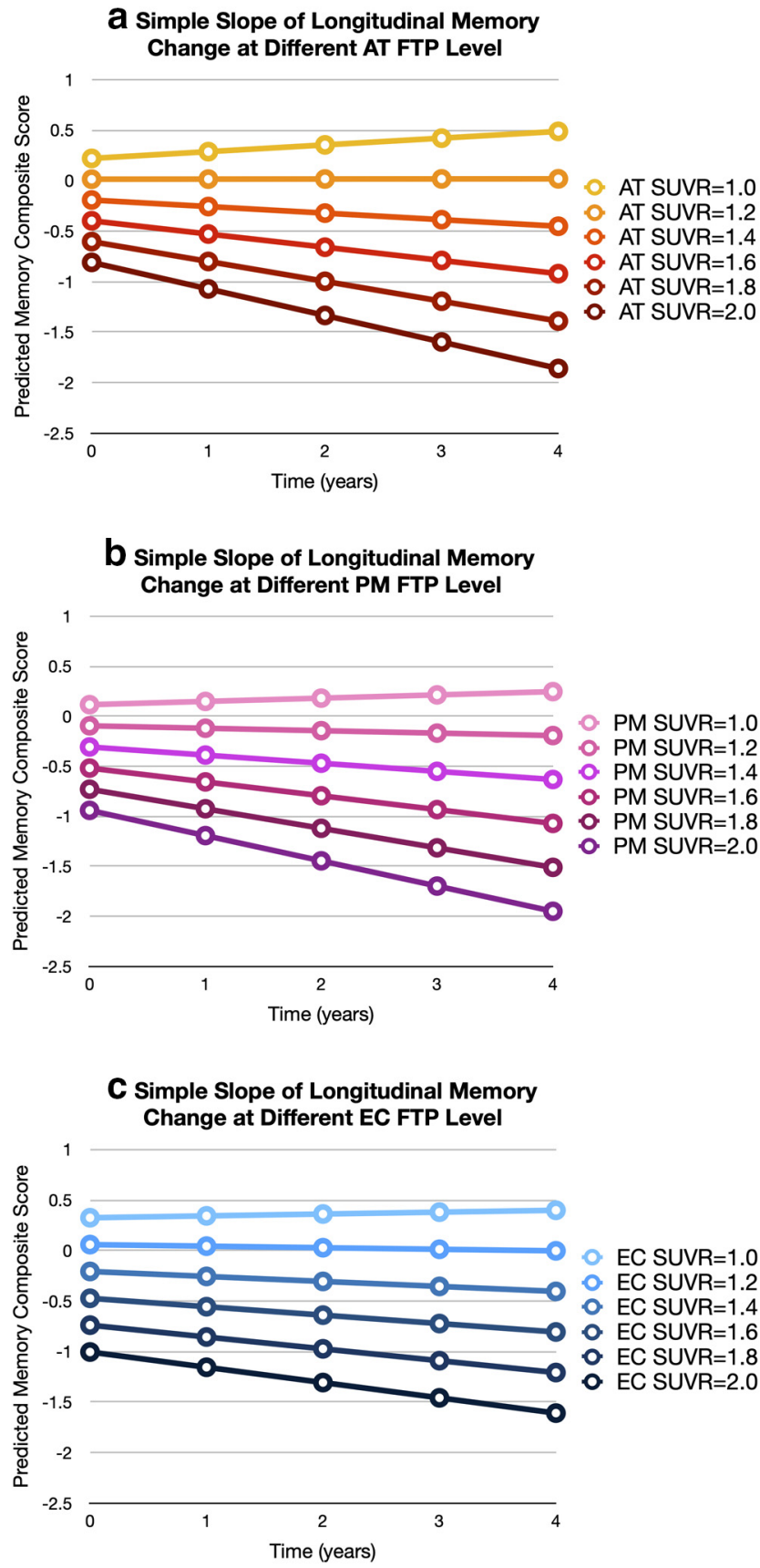

Figure 1. Higher $\operatorname{AT}(\boldsymbol{a}), \operatorname{PM}(\boldsymbol{b})$, and $\mathrm{EC}(\boldsymbol{c})$ tau associated with faster prospective memory decline. Simple slopes of FTP effect on longitudinal memory are depicted while holding other variables fixed at the sample mean. Higher FTP SUVR in all three regions is associated with a steeper declining slope.

greater effect on longitudinal memory change as PiB DVR increased (AT: $p=0.001, \mathrm{PM}: p=0.018$ ), while the EC FTP $\times$ $\mathrm{PiB}$ DVR $\times$ time interaction was not statistically significant, although trending $(p=0.085)$.

Using a continuous $\mathrm{A} \beta$ measure also allowed us to explore the global PiB DVR value at which regional tau starts to affect memory as $\mathrm{A} \beta$ accumulates. We found that the effect of AT FTP on memory change was significant after PiB DVR reached a value of 1.17, equivalent to $25 \mathrm{CL}$. Similarly, the PM FTP effect on memory change became significant as PiB DVR increased to 1.13 (19 CL). In contrast, the EC FTP effect was significant even at very low $\mathrm{PiB}$ DVRs (inflection $\mathrm{PiB} \mathrm{DVR}=0.95, \mathrm{CL}=-7$ ), 
consistent with the finding suggesting a significant EC FTP effect on memory change across $\mathrm{A} \beta$ groups.

Regional tau measures simultaneously predict prospective memory change We examined whether tau in AT was the strongest predictor of memory change above and beyond EC and PM tau by simultaneously modeling multiple FTP measures (Table 3). In the model with AT and EC FTP, we found that AT FTP significantly predicted longitudinal memory change $(p=0.048)$, whereas EC FTP only had a main effect on memory performance $(p<0.001$; for all statistics, see Extended Data Table 3-1). When additionally including $\mathrm{A} \beta$ status in the model, AT FTP $\times$ time $\times$ A $\beta$ status was significant $(p=0.025)$, revealing a stronger effect of AT FTP in A $\beta+$ individuals.

In contrast, we did not find any significant PM FTP effect $(p=0.33)$ when PM and EC FTP SUVRs were both included in the model. Including $A \beta$ status did not change the result $(p=$ 0.27 ; for statistics of all predictors, see Extended Data Table 3-2).

When including both AT and PM FTP SUVRs in the model (for statistics of all predictors, see Extended Data Table 33), AT FTP still had a significant effect on memory change $(p=0.011)$, whereas PM FTP did not $(p=0.36)$. This AT FTP effect was stronger in $\mathrm{A} \beta+$ individuals $(p=0.035)$.

Finally, we simultaneously modeled all three FTP measures to explore their unique effects when they were competitively included in the same model (for statistics, see Extended Data Table 3-4). As depicted in Figure 4, we found that while EC FTP SUVR was strongly related to cross-sectional memory performance $(p<0.001)$, AT FTP SUVR was the only significant predictor of longitudinal memory change among the three FTP measures $(p=0.045)$. This strongest effect of AT FTP $\times$ time was primarily driven by $\mathrm{A} \beta+$ individuals $(p=0.032)$.

\section{Confirmatory analyses of at and PM}

subregions, hippocampal and EC neurodegeneration,

white matter lesion, and executive function

To further confirm and interpret our results, we conducted a series of supplementary analyses. First, we repeated the primary analyses for each subregion that constitutes the AT and PM ROIs. Higher FTP SUVR in inferior temporal and fusiform both predicted prospective memory decline beyond EC FTP, particularly in $\mathrm{A} \beta+$ individuals (inferior temporal: $p=0.025$, Fusiform: $p=0.018$ ), whereas amygdala FTP was not significantly related to memory change when EC FTP was in the model $(p=0.76)$. For PM subregions, results largely replicated a AT FTP Predicts Longitudinal Memory Change in A $\beta+$ Group
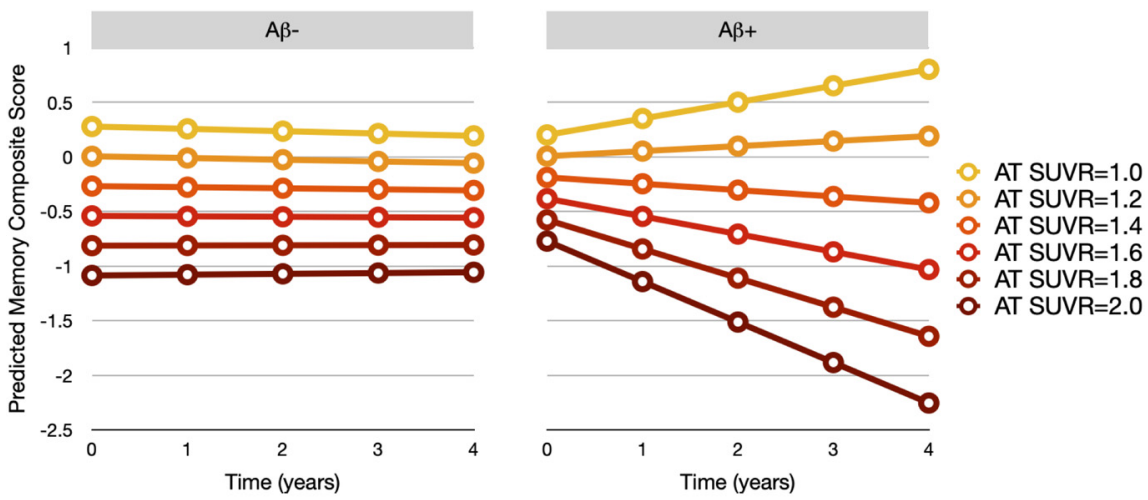

b PM FTP Predicts Longitudinal Memory Change in A $\beta+$ Group
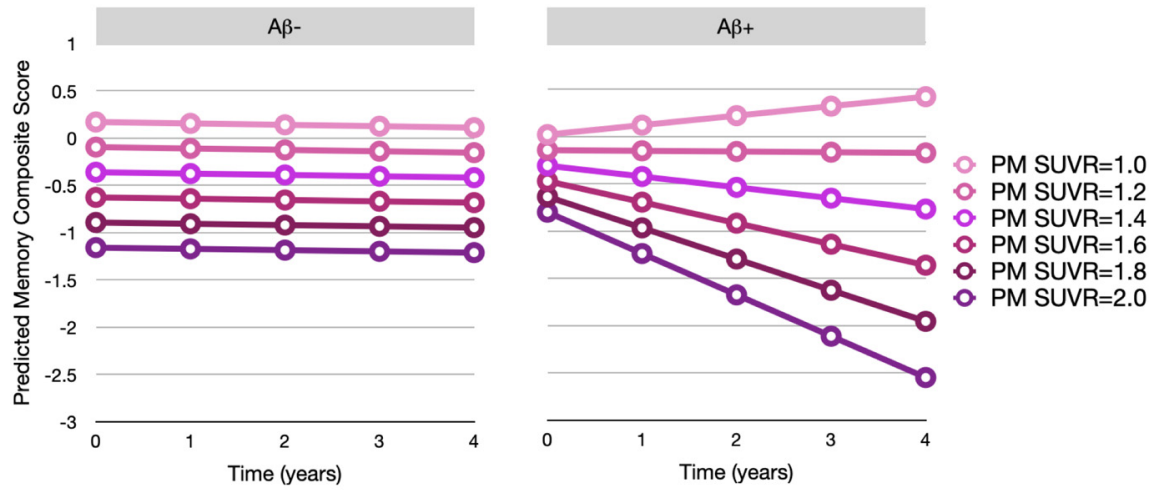

C EC FTP Predicts Longitudinal Memory Change
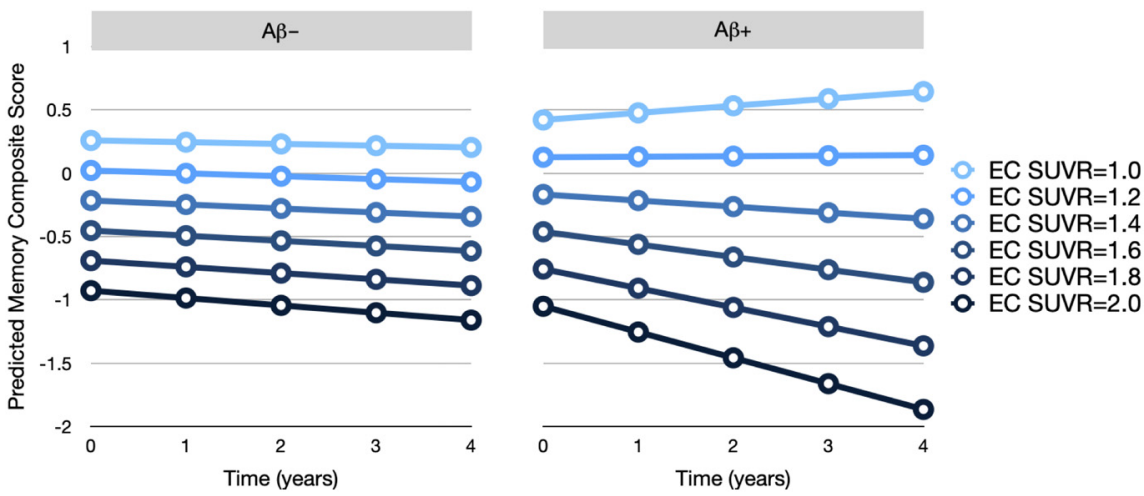

Figure 2. $\mathrm{AT}(\boldsymbol{a}), \mathrm{PM}(\boldsymbol{b})$, and $\mathrm{EC}(\boldsymbol{c})$ tau effects on prospective memory change in $\mathrm{A} \beta$ - and $\mathrm{A} \beta+$ individuals. Simple slopes of FTP effect in $A \beta$ - and $A \beta+$ groups on longitudinal memory are separately depicted while holding other variables fixed at the sample mean. The effect of tau in AT and PM is moderated by A $\beta$ status: higher FTP SUVR is only associated with a steeper declining slope in the $A \beta+$ group. the primary finding: higher regional FTP SUVR was individually related to greater longitudinal memory decline for all three subregions (parahippocampal: $p=0.002$, isthmus cingulate: $p=0.037$, precuneus: $p=0.039$ ), but the effect diminished when EC FTP SUVR was additionally included (parahippocampal: $p=0.11$, isthmus cingulate: $p=0.33$, precuneus: $p=0.46$ ).

Next, we investigated whether the FTP effect on memory decline was confounded by individual differences in neurodegeneration. We used hippocampal volume (adjusted for estimated total intracranial volume) and EC thickness as indices and examined whether their inclusion in the models changed any of the findings. We found that hippocampal volume did not predict 

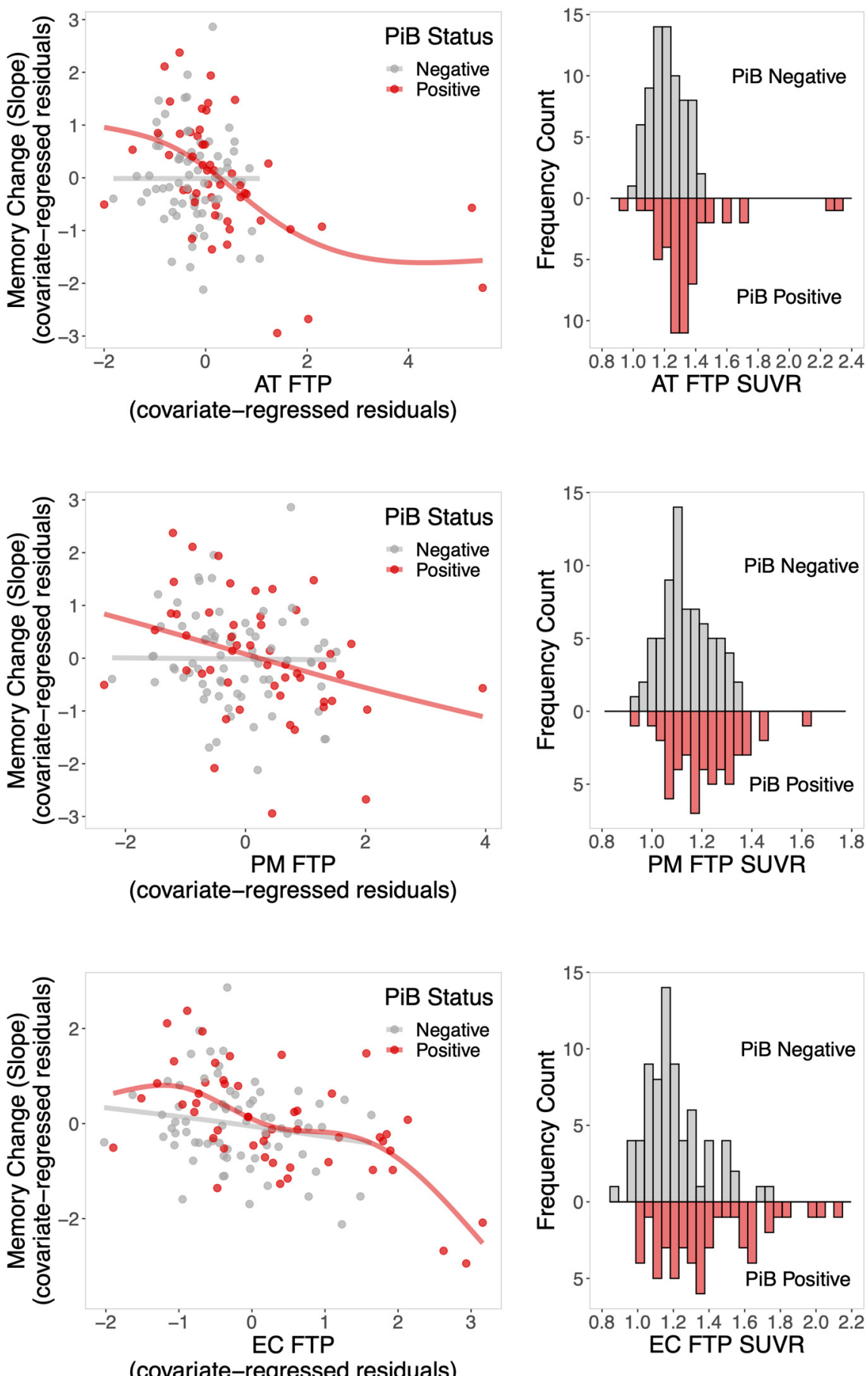

Figure 3. Relationship between $\mathrm{AT}, \mathrm{PM}, \mathrm{EC}$ tau, and memory change (slope) in $\mathrm{A} \beta$ - and $\mathrm{A} \beta+$ individuals after controlling for age, sex, education, APOE status, and cog-PET interval. The individual memory change (slope) was extracted using a simple LMM with time as the only predictor. The covariate-regressed standardized residuals are plotted. Group lines are separately fit for $A \beta$ - and $A \beta+$ individuals using generalized additive model (GAM) smoothing to show group trends. Histograms illustrate the distribution of regional FTP burden, separated by PiB status (top: negative; bottom: positive). For raw relationships, see Extended Data Figure 3-1.

memory change in any analysis and did not change any findings we reported. Thinner EC, on the other hand, was related to faster memory decline in several models $(p s<0.05)$. But FTP effects remained unchanged, suggesting a primary tau influence on memory decline beyond neurodegeneration.

We also considered the potential influence of the load of vascular insults (Kim et al., 2018) by examining the effect of white matter lesions on memory change. We incorporated the white matter hypointensity measure (Dadar et al., 2018; Wei et al., 2019) derived from FreeSurfer using the T1-weighted images. We found that white matter hypointensity was related to worse cross-sectional memory performance ( $p s<0.05$ ), but did not predict longitudinal memory change, and did not change any of our findings.

Finally, we explored whether the reported FTP effects on memory also applied to executive function, and repeated the primary analyses using executive function as the outcome variable in the models. We did not find any significant effect of FTP in AT, PM, or EC on executive function change ( $p s>0.1$ ), suggesting a specific effect of early tau on memory in this healthy cohort.

\section{Discussion}

Our study investigated regional tau effects on prospective cognitive change in 124 cognitively normal older adults. We found that having greater tau predicted faster memory decline, consistent with previous findings of prospectively measured cognition (Hanseeuw et al., 2019; Sperling et al., 2019). Specifically, we found interesting regional differences in which tau burden in AT and PM regions was predictive of memory decline exclusively in individuals harboring $\mathrm{A} \beta$, whereas the EC tau effect appeared to be independent of $\mathrm{A} \beta$ pathology. Moreover, AT tau had the strongest effect on memory change above and beyond EC and PM tau effects. Altogether, our study suggests differential contributions of regional tau to memory decline, potentially revealing a sequential influence of tau pathology in $\mathrm{EC}, \mathrm{AT}$, and $\mathrm{PM}$ regions on prospectively measured cognition.

High EC tau was found to be related to worse cross-sectional memory and greater memory decline preceding $\mathrm{A} \beta$ deposition, suggesting an initial effect of EC tau on cognition in older adults with little AD pathology. This finding is consistent with the concept of primary agerelated tauopathy (PART; Crary et al., 2014), which describes a common pathology in older brains of high tau accumulation with little evidence of $\mathrm{A} \beta$. Whether or not PART belongs on the AD continuum is debated (Duyckaerts et al., 2015; Bell et al., 2019), and recent research on its clinical consequences yielded mixed findings (JeffersonGeorge et al., 2017; Schöll and Maass, 2020; Teylan et al., 2020). Our findings seem to agree with previous pathologic (JeffersonGeorge et al., 2017; Josephs et al., 2017) and cross-sectional 
Table 3. Regression statistic for the effects of FTP $\times$ time and FTP $\times$ a $\beta$ status $\times$ time in models with multiple tau predictors

\begin{tabular}{|c|c|c|c|c|}
\hline & & $\begin{array}{l}\mathrm{ROI}_{1}: \mathrm{AT} \\
\mathrm{ROI}_{2}: \mathrm{EC}\end{array}$ & $\begin{array}{l}\mathrm{ROI}_{1}: \mathrm{PM} \\
\mathrm{ROI}_{2}: \mathrm{EC}\end{array}$ & $\begin{array}{l}\mathrm{ROI}_{1}: \mathrm{AT} \\
\mathrm{ROI}_{2}: \mathrm{PM}\end{array}$ \\
\hline \multicolumn{5}{|c|}{$\begin{array}{l}\text { Model 3: memory } \sim \text { sex }+ \text { age }+ \text { education }+ \text { APOE }+ \text { Cog-PET interval }+\mathrm{ROI}_{1} \\
\mathrm{FTP}+\mathrm{ROI}_{2} \mathrm{FTP}+\text { time }+ \text { age } \times \text { time }+ \text { sex } \times \text { time }+ \text { education } \times \text { time }+ \\
\mathrm{APOE} \times \text { time }+ \text { Cog-PET interval } \times \text { time }+\mathrm{ROI}_{1} \mathrm{FTP} \times \text { time }+\mathrm{ROI}_{2} \mathrm{FTP} \times \\
\text { time }+ \text { random slope }+ \text { random intercept }\end{array}$} \\
\hline $\mathrm{ROI}_{1} \mathrm{FTP} \times$ time & & $\begin{array}{l}-0.27(0.14) \\
0.048^{*}\end{array}$ & $\begin{array}{l}-0.15(0.15) \\
0.33\end{array}$ & $\begin{array}{l}-0.48(0.19 \\
0.011^{*}\end{array}$ \\
\hline $\mathrm{ROI}_{2} \mathrm{FTP} \times$ time & & $\begin{array}{l}-0.04(0.10) \\
0.70\end{array}$ & $\begin{array}{l}-0.12(0.08) \\
0.13\end{array}$ & $\begin{array}{l}0.22(0.2 \\
0.36\end{array}$ \\
\hline \multicolumn{5}{|c|}{$\begin{array}{l}\text { Model 4: memory } \sim \text { sex }+ \text { age }+ \text { education }+\mathrm{APOE}+\mathrm{Cog} \text {-PET interval }+\mathrm{ROI}_{1} \\
\mathrm{FTP}+\mathrm{ROI}_{2} \mathrm{FTP}+\mathrm{A} \beta \text { status }+ \text { time }+\mathrm{ROI}_{1} \mathrm{FTP} \times \mathrm{A} \beta \text { status }+\mathrm{ROI}_{2} \mathrm{FTP} \times \\
\mathrm{A} \beta \text { status }+ \text { age } \times \text { time }+ \text { sex } \times \text { time }+ \text { education } \times \text { time }+\mathrm{APOE} \times \text { time }+ \\
\mathrm{Cog}-\mathrm{PET} \text { interval } \times \text { time }+\mathrm{A} \beta \text { status } \times \text { time }+\mathrm{ROI}_{1} \mathrm{FTP} \times \text { time }+\mathrm{ROI} \mathrm{I}_{2} \mathrm{FTP} \times \\
\text { time }+\mathrm{ROI}_{1} \mathrm{FTP} \times \mathrm{A} \beta \text { status } \times \text { time }+\mathrm{ROI}_{2} \mathrm{FTP} \times \mathrm{A} \beta \text { status } \times \text { time }+ \\
\text { random slope }+ \text { random intercept }\end{array}$} \\
\hline $\mathrm{ROI}_{1} \mathrm{FTP} \times \mathrm{A} \beta$ status $\times$ time & & $\begin{array}{l}-0.63(0.27) \\
0.025^{*}\end{array}$ & $\begin{array}{l}-0.34(0.31) \\
0.27\end{array}$ & $\begin{array}{l}-0.91(0.42 \\
0.035^{*}\end{array}$ \\
\hline 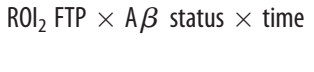 & $b$ (se) & $\begin{array}{l}0.09 \text { (0. } \\
0.62\end{array}$ & $\begin{array}{l}-0.11(0.17) \\
0.52\end{array}$ & $\begin{array}{l}0.48(0.48) \\
0.32\end{array}$ \\
\hline
\end{tabular}

$* p<0.05$. For statistics of all predictors, see Extended Data Tables 3-1 (at and EC), 3-2 (PM and EC), 3-3 (at and PM), and 3-4 (at, PM, and EC).

evidence (Shimada et al., 2017; Groot et al., 2020; Weigand et al., 2020) that tau in EC may exert a detrimental effect on memory without the necessity of $\mathrm{A} \beta$ (Maass et al., 2018). There have also been reports that EC tau does not affect cognition in the absence of $\mathrm{A} \beta$ (Sperling et al., 2019). The contrast between these findings and the present study can be illustrated by comparing results from Sperling et al. (2019; Fig. 2A) with ours (Fig. 3, EC plot); results in the high tau range are similar, while our results also show a relationship between EC tau and memory change even in the low tau range where theirs did not. Our sample was slightly smaller, more highly educated, and with a lower proportion of $A P O E \varepsilon 4$ carriers, none of which seem likely to explain the differences. However, our sample, particularly the $\mathrm{A} \beta$ - group, appeared to have more memory decline with greater variability, possibly because of their slightly older age and longer follow-up time, which may contribute to the result differences. Altogether, we believe that increases in EC tau are likely to affect memory without $\mathrm{A} \beta$ pathology, possibly underlying age-related memory loss in normal aging. Elevated $\mathrm{A} \beta$ further accelerates this tau effect in preclinical $\mathrm{AD}$, possibly by increasing the toxicity of the accumulated tau and also facilitating its further spread to the neocortex (Pooler et al., 2015).

We found that AT tau was the strongest predictor of prospective memory change among the three regions we investigated, particularly in those harboring $\mathrm{A} \beta$. This likely reflects a transition from an age-related to an $\mathrm{AD}$-related tau effect as the primary determinant of memory in preclinical $\mathrm{AD}$, following the spread of tau from EC to AT regions. Our finding that the PM tau effect diminished when the stronger influence of AT tau was taken into account may reflect the lower amount of tau accumulation in PM in cognitively normal older people. This is consistent with the observation that a lower PM FTP SUVR than AT FTP SUVR was associated with the initiation of negative memory change. It is likely that in later stages (e.g., MCI), PM tau may play a more important role in predicting cognitive decline in symptomatic patients.

The thresholds for both FTP effects on memory (SUVR $\approx$ $1.3)$ and $\mathrm{A} \beta$ effects on tau $(\mathrm{DVR} \approx 1.17,25 \mathrm{CL})$ are also informative. While there is no clear consensus on either brain regions or threshold values defining a "positive" tau PET scan, the FTP SUVR value identified is in the range of proposed thresholds albeit for other brain regions (Jack et al., 2017; Maass et al., 2017). This is perhaps not surprising since thresholds are often generated through comparisons of impaired versus normal individuals; nevertheless, this general range of FTP SUVRs seems to have biological significance. We note that the identified SUVR values in this study were based on PVC-corrected data, which may increase the values when compared with other non-PVC SUVR values. Similarly, the global A $\beta$ at which neocortical tau starts to become behaviorally detrimental is $\sim 19-25 \mathrm{CL}$, which falls within the range of $\mathrm{A} \beta$ thresholds for moderate neuropathology and $\mathrm{A} \beta$ positivity based on autopsy studies (Navitsky et al., 2018; La Joie et al., 2019; Amadoru et al., 2020). Studies have also shown that $\mathrm{A} \beta$ burden below positivity thresholds can still predict longitudinal cognitive decline in cognitively normal individuals (Farrell et al., 2018; Landau et al., 2018). It is important to recognize that the $\mathrm{A} \beta$ thresholds suggested here in the study indicate levels at which $\mathrm{A} \beta$ exerts effects on tau that are cognitively relevant; it is possible that $\mathrm{A} \beta$ may produce detrimental effects at lower levels because they are associated with undetectable increases in tau. Nevertheless, these findings are important for identifying individuals at most risk of prospective cognitive decline because of $\mathrm{AD}$ pathology, who may benefit most from $\mathrm{A} \beta$ lowering therapeutic interventions.

The AT and PM networks investigated in the study are both functionally connected to the EC, but to different subregions: the $\mathrm{AT}$ region to anterolateral EC and $\mathrm{PM}$ to posteromedial EC (Maass et al., 2015; Schröder et al., 2015). Accumulating evidence suggests that tau spreads through neural connectivity in AD (Liu et al., 2012; Hoenig et al., 2018; Franzmeier et al., 2019). Recently, investigating BACS participants that overlapped with this study, our lab reported that tau preferentially deposits in the AT network (Maass et al., 2019), and showed strong evidence that this is related to patterns of anterolateral EC connectivity (Adams et al., 2019). Cortical tau deposition likely initiates in the transentorhinal region (Braak and Braak, 1992, 1995), a site comprising anterolateral EC and the medial aspect of perirhinal cortex. We thus interpret our finding that AT tau affects cognition more strongly than EC or PM tau as reflecting the earliest spread of tau out of the medial temporal lobe (MTL) to AT targets from anterolateral EC. Other recent BACS data from our laboratory has shown that AT tau appears to disconnect the hippocampus from other components of the MTL memory system, which in turn is related to episodic memory decline (Harrison et al., 2019). Based on this evidence and our current findings, we suggest that the pathophysiology of the progression from normal aging to $\mathrm{AD}$ involves the spread of tau from anterolateral EC to AT regions, disconnection of hippocampal function, and episodic memory decline. We found that these events appear to be specific to memory, congruent with the typical initiation of $\mathrm{AD}$ as an amnestic syndrome. Moreover, evidence has shown that difficulties in object processing are prevalent in normal aging, while spatial memory is often better preserved; whereas impaired individuals often have difficulties with both object and spatial processing (Binetti et al., 1998; Reagh et al., 2016). This also supports the idea of a sequential impact of tau pathology in the AT and PM memory networks. We suspect that as tau spreads into brain areas with different functional specialization, or as the disease progresses to later stages (Koran et al., 2017; Visser et al., 2020), other cognitive functions eventually become affected (Digma et al., 2019; Sun et al., 2019). 

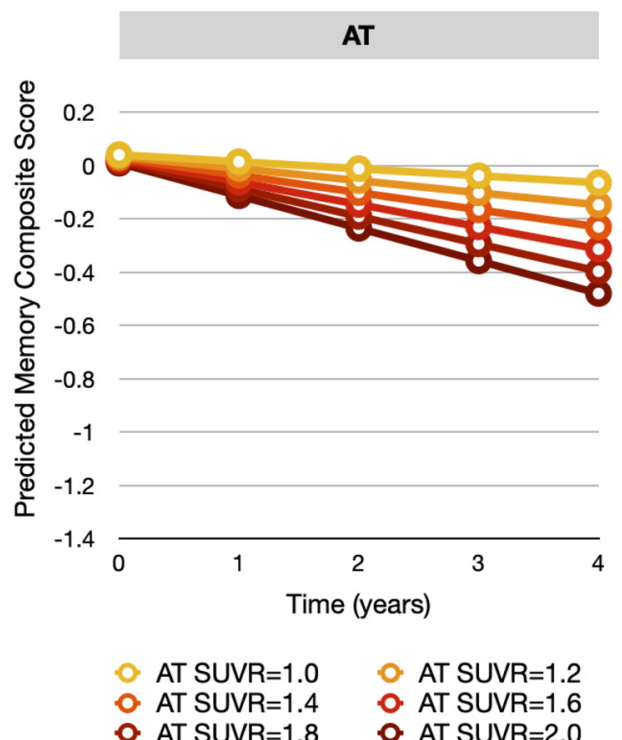
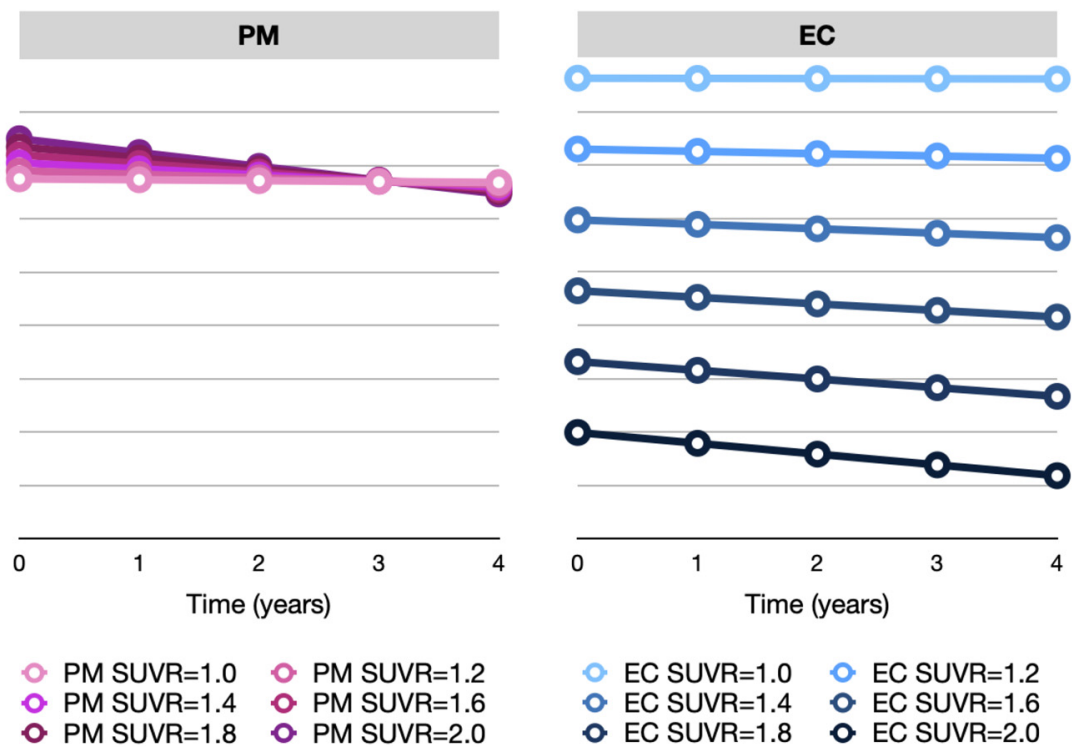
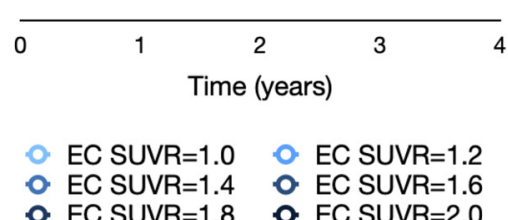

Figure 4. AT tau effect on longitudinal memory decline above and beyond PM and EC tau.

While our study has many strengths, including its multimodal nature, the moderate period of prospective follow-up, and the convergence of results consistent with previous findings, it does have limitations. The FTP tracer has shown evidence of off-target binding and lack of specificity in some regions (Marquié et al., 2015; Baker et al., 2019; Lowe et al., 2020). However, the ROIs we investigated are not particularly susceptible to these effects, and we conducted partial volume correction to further control for this problem. Although the follow-up time was moderate by current standards, it is possible that some non-significant effects would become significant with longer testing intervals. Finally, our cohort is highly educated and does not fully represent the diversity of older individuals across the United States.

In conclusion, our data support a model whereby tau transits from the MTL to cortical targets that are most closely associated with anterolateral EC in a pattern facilitated by $\mathrm{A} \beta$, which has specific effects on prospective memory decline. This may represent the initial stage of $\mathrm{AD}$, and occurs when $\mathrm{A} \beta$ levels cross a general threshold of positivity. There appear to be additional effects of EC tau on longitudinal memory decline that are not dependent on $\mathrm{A} \beta$, which may be less clinically consequential. Together, these findings provide clarification of differences between normal aging and preclinical $\mathrm{AD}$ and elucidate the transitions between the two stages.

\section{References}

Adams JN, Maass A, Harrison TM, Baker SL, Jagust WJ (2019) Cortical tau deposition follows patterns of entorhinal functional connectivity in aging. Elife 8:e49132.

Aiken LS, West SG, Reno RR (1991) Multiple regression: testing and interpreting interactions. Thousand Oaks: SAGE Publications.

Amadoru S, Doré V, McLean CA, Hinton F, Shepherd CE, Halliday GM, Leyton CE, Yates PA, Hodges JR, Masters CL (2020) Comparison of amyloid PET measured in Centiloid units with neuropathological findings in Alzheimer's disease. Alzheimers Res Ther 12:1-8.

Aschenbrenner AJ, Gordon BA, Benzinger TLS, Morris JC, Hassenstab JJ (2018) Influence of tau PET, amyloid PET, and hippocampal volume on cognition in Alzheimer disease. Neurology 91:e859-e866.

Baker SL, Maass A, Jagust WJ (2017) Considerations and code for partial volume correcting [18F]-AV-1451 tau PET data. Data Brief 15:648-657.

Baker SL, Harrison TM, Maass A, La Joie R, Jagust WJ (2019) Effect of offtarget binding on 18F-Flortaucipir variability in healthy controls across the life span. J Nucl Med 60:1444-1451.
Bell WR, An Y, Kageyama Y, English C, Rudow GL, Pletnikova O, Thambisetty M, O’Brien R, Moghekar AR, Albert MS, Rabins PV, Resnick SM, Troncoso JC (2019) Neuropathologic, genetic, and longitudinal cognitive profiles in primary age-related tauopathy (PART) and Alzheimer's disease. Alzheimers Dement 15:8-16.

Betthauser TJ, Koscik RL, Jonaitis EM, Allison SL, Cody KA, Erickson CM, Rowley HA, Stone CK, Mueller KD, Clark LR, Carlsson CM, Chin NA, Asthana S, Christian BT, Johnson SC (2020) Amyloid and tau imaging biomarkers explain cognitive decline from late middle-age. Brain 143:320-335.

Binetti G, Cappa SF, Magni E, Padovani A, Bianchetti A, Trabucchi M (1998) Visual and spatial perception in the early phase of Alzheimer's disease. Neuropsychology 12:29-33.

Braak H, Braak E (1992) The human entorhinal cortex: normal morphology and lamina-specific pathology in various diseases. Neurosci Res 15:6-31.

Braak H, Braak EVA (1995) Staging of Alzheimer's disease-related neurofibrillary changes. Neurobiol Aging 16:271-278.

Braak E, Braak H (1997) Alzheimer's disease: transiently developing dendritic changes in pyramidal cells of sector CA1 of the Ammon's horn. Acta Neuropathol 93:323-325.

Cho H, Choi JY, Hwang MS, Kim YJ, Lee HM, Lee HS, Lee JH, Ryu YH, Lee MS, Lyoo CH (2016) In vivo cortical spreading pattern of tau and amyloid in the Alzheimer disease spectrum. Ann Neurol 80:247-258.

Crary JF, Trojanowski JQ, Schneider JA, Abisambra JF, Abner EL, Alafuzoff I, Arnold SE, Attems J, Beach TG, Bigio EH, Cairns NJ, Dickson DW, Gearing M, Grinberg LT, Hof PR, Hyman BT, Jellinger K, Jicha GA, Kovacs GG, Knopman DS, et al. (2014) Primary age-related tauopathy (PART): a common pathology associated with human aging. Acta Neuropathol 128:755-766.

Dadar M, Maranzano J, Ducharme S, Carmichael OT, Decarli C, Collins DL, Initiative ADN; Alzheimer's Disease Neuroimaging Initiative (2018) Validation of $\mathrm{T} 1 \mathrm{w}$-based segmentations of white matter hyperintensity volumes in large-scale datasets of aging. Hum Brain Mapp 39:1093-1107.

Delis DC, Kramer JH, Kaplan E, Ober BA (2000) California Verbal Learning Test-Second Edition (CVLT-II). San Antonio: Psychol Corp.

Desikan RS, Ségonne F, Fischl B, Quinn BT, Dickerson BC, Blacker D, Buckner RL, Dale AM, Maguire RP, Hyman BT, Albert MS, Killiany RJ (2006) An automated labeling system for subdividing the human cerebral cortex on MRI scans into gyral based regions of interest. Neuroimage 31:968-980.

Digma LA, Madsen JR, Reas ET, Dale AM, Brewer JB, Banks SJ; Alzheimer's Disease Neuroimaging Initiative (2019) Tau and atrophy: domain-specific relationships with cognition. Alzheimers Res Ther 11:65.

Duyckaerts C, Braak H, Brion J-P, Buée L, Del Tredici K, Goedert M, Halliday G, Neumann M, Spillantini MG, Tolnay M, Uchihara T (2015) PART is part of Alzheimer disease. Acta Neuropathol 129:749-756. 
Farrell ME, Chen X, Rundle MM, Chan MY, Wig GS, Park DC (2018) Regional amyloid accumulation and cognitive decline in initially amyloid-negative adults. Neurology 91:e1809-e1821.

Franzmeier N, Rubinski A, Neitzel J, Kim Y, Damm A, Na DL, Kim HJ, Lyoo $\mathrm{CH}$, Cho H, Finsterwalder S, Duering M, Seo SW, Ewers M; Alzheimer's Disease Neuroimaging Initiative (2019) Functional connectivity associated with tau levels in ageing, Alzheimer's, and small vessel disease. Brain 142:1093-1107.

Groot C, Doré V, Robertson J, Burnham S, Savage G, Ossenkoppele R, Rowe CC, Villemagne VL (2020) Mesial temporal tau is related to worse cognitive performance and greater neocortical tau load in $\beta$-amyloid negative cognitively normal individuals. Neurobiol Aging 97:41-48.

Hanseeuw BJ, Betensky RA, Jacobs HIL, Schultz AP, Sepulcre J, Becker JA, Cosio DMO, Farrell M, Quiroz YT, Mormino EC, Buckley RF, Papp KV, Amariglio RA, Dewachter I, Ivanoiu A, Huijbers W, Hedden T, Marshall GA, Chhatwal JP, Rentz DM, et al. (2019) Association of amyloid and tau with cognition in preclinical Alzheimer disease: a longitudinal study. JAMA Neurol 76:915-924.

Harrison TM, Maass A, Adams JN, Du R, Baker SL, Jagust WJ (2019) Tau deposition is associated with functional isolation of the hippocampus in aging. Nat Commun 10:4900.

Hoenig MC, Bischof GN, Seemiller J, Hammes J, Kukolja J, Onur Ö, A, Jessen F, Fliessbach K, Neumaier B, Fink GR, van Eimeren T, Drzezga A (2018) Networks of tau distribution in Alzheimer's disease. Brain 141:568-581.

Inhoff MC, Ranganath C (2017) Dynamic cortico-hippocampal networks underlying memory and cognition: the PMAT framework. In: The hippocampus from cells to systems, pp 559-589. New York: Springer.

Jack CR, Knopman DS, Jagust WJ, Petersen RC, Weiner MW, Aisen PS, Shaw LM, Vemuri P, Wiste HJ, Weigand SD, Lesnick TG, Pankratz VS, Donohue MC, Trojanowski JQ (2013) Tracking pathophysiological processes in Alzheimer's disease: an updated hypothetical model of dynamic biomarkers. Lancet Neurol 12:207-216.

Jack CR, Wiste HJ, Weigand SD, Therneau TM, Lowe VJ, Knopman DS, Gunter JL, Senjem ML, Jones DT, Kantarci K, Machulda MM, Mielke MM, Roberts RO, Vemuri P, Reyes DA, Petersen RC (2017) Defining imaging biomarker cut points for brain aging and Alzheimer's disease. Alzheimers Dement 13:205-216.

Jack CR, Wiste HJ, Botha H, Weigand SD, Therneau TM, Knopman DS, Graff-Radford J, Jones DT, Ferman TJ, Boeve BF, Kantarci K, Lowe VJ, Vemuri P, Mielke MM, Fields JA, Machulda MM, Schwarz CG, Senjem ML, Gunter JL, Petersen RC (2019) The bivariate distribution of amyloid- $\beta$ and tau: relationship with established neurocognitive clinical syndromes. Brain 142:3230-3242.

James G, Witten D, Hastie T, Tibshirani R (2013) An introduction to statistical learning. New York: Springer.

Jefferson-George KS, Wolk DA, Lee EB, McMillan CT (2017) Cognitive decline associated with pathological burden in primary age-related tauopathy. Alzheimers Dement 13:1048-1053.

Johnson PO, Fay LC (1950) The Johnson-Neyman technique, its theory and application. Psychometrika 15:349-367.

Johnson KA, Schultz A, Betensky RA, Becker JA, Sepulcre J, Rentz D, Mormino E, Chhatwal J, Amariglio R, Papp K, Marshall G, Albers M, Mauro S, Pepin L, Alverio J, Judge K, Philiossaint M, Shoup T, Yokell D, Dickerson B, et al. (2016) Tau positron emission tomographic imaging in aging and early A lzheimer disease. Ann Neurol 79:110-119.

Josephs KA, Murray ME, Tosakulwong N, Whitwell JL, Knopman DS, Machulda MM, Weigand SD, Boeve BF, Kantarci K, Petrucelli L, Lowe VJ, Jack CR, Petersen RC, Parisi JE, Dickson DW (2017) Tau aggregation influences cognition and hippocampal atrophy in the absence of betaamyloid: a clinico-imaging-pathological study of primary age-related tauopathy (PART). Acta Neuropathol 133:705-715.

Kerr KM, Agster KL, Furtak SC, Burwell RD (2007) Functional neuroanatomy of the parahippocampal region: the lateral and medial entorhinal areas. Hippocampus 17:697-708.

Kim HJ, Park S, Cho H, Jang YK, San Lee J, Jang H, Kim Y, Kim KW, Ryu YH, Choi JY, Moon SH, Weiner MW, Jagust WJ, Rabinovici GD, DeCarli C, Lyoo CH, Na DL, Seo SW (2018) Assessment of extent and role of tau in subcortical vascular cognitive impairment using $18 \mathrm{~F}-$ AV1451 positron emission tomography imaging. JAMA Neurol 75:9991007.
Klunk WE, Koeppe RA, Price JC, Benzinger TL, Devous MD, Jagust WJ, Johnson KA, Mathis CA, Minhas D, Pontecorvo MJ, Rowe CC, Skovronsky DM, Mintun MA (2015) The Centiloid Project: standardizing quantitative amyloid plaque estimation by PET. Alzheimers Dement 11:1-15.

Koran MEI, Wagener M, Hohman TJ; Alzheimer's Neuroimaging Initiative (2017) Sex differences in the association between AD biomarkers and cognitive decline. Brain Imaging Behav 11:205-213.

La Joie R, Ayakta N, Seeley WW, Borys E, Boxer AL, DeCarli C, Doré V, Grinberg LT, Huang E, Hwang JH, Ikonomovic MD, Jack C, Jagust WJ, Jin LW, Klunk WE, Kofler J, Lesman-Segev OH, Lockhart SN, Lowe VJ, Masters CL, et al. (2019) Multisite study of the relationships between antemortem [11 C]PIB-PET Centiloid values and postmortem measures of Alzheimer's disease neuropathology. Alzheimers Dement 15:205-216.

Landau SM, Horng A, Jagust WJ; Alzheimer's Disease Neuroimaging Initiative (2018) Memory decline accompanies subthreshold amyloid accumulation. Neurology 90:E1452-E1460.

Liu L, Drouet V, Wu JW, Witter MP, Small SA, Clelland C, Duff K (2012) Trans-synaptic spread of tau pathology in vivo. PLoS One 7:e31302.

Logan J, Fowler JS, Volkow ND, Wang G-J, Ding YS, Alexoff DL (1996) Distribution volume ratios without blood sampling from graphical analysis of PET data. J Cereb Blood Flow Metab 16:834-840.

Lowe VJ, Lundt ES, Albertson SM, Min H-K, Fang P, Przybelski SA, Senjem ML, Schwarz CG, Kantarci K, Boeve B (2020) Tau-positron emission tomography correlates with neuropathology findings. Alzheimers Dement 16:561-571.

Maass A, Berron D, Libby LA, Ranganath C, Düzel E (2015) Functional subregions of the human entorhinal cortex. Elife 4:e06426.

Maass A, Landau S, Horng A, Lockhart SN, Rabinovici GD, Jagust WJ, Baker SL, La Joie R; Alzheimer's Disease Neuroimaging Initiative (2017) Comparison of multiple tau-PET measures as biomarkers in aging and Alzheimer's disease. Neuroimage 157:448-463.

Maass A, Lockhart SN, Harrison TM, Bell RK, Mellinger T, Swinnerton K, Baker SL, Rabinovici GD, Jagust WJ (2018) Entorhinal tau pathology, episodic memory decline, and neurodegeneration in aging. J Neurosci 38:530-543.

Maass A, Berron D, Harrison TM, Adams JN, La Joie R, Baker S, Mellinger T, Bell RK, Swinnerton K, Inglis B, Rabinovici GD, Düzel E, Jagust WJ (2019) Alzheimer's pathology targets distinct memory networks in the ageing brain. Brain 142:2492-2509.

Marquié M, Normandin MD, Vanderburg CR, Costantino IM, Bien EA, Rycyna LG, Klunk WE, Mathis CA, Ikonomovic MD, Debnath ML, Vasdev N, Dickerson BC, Gomperts SN, Growdon JH, Johnson KA, Frosch MP, Hyman BT, Gómez-Isla T (2015) Validating novel tau positron emission tomography tracer [F-18]-AV-1451 (T807) on postmortem brain tissue. Ann Neurol 78:787-800.

Mormino EC, Brandel MG, Madison CM, Rabinovici GD, Marks S, Baker SL, Jagust WJ (2012) Not quite PIB-positive, not quite PIB-negative: slight PIB elevations in elderly normal control subjects are biologically relevant. Neuroimage 59:1152-1160.

Navitsky M, Joshi AD, Kennedy I, Klunk WE, Rowe CC, Wong DF, Pontecorvo MJ, Mintun MA, Devous MD (2018) Standardization of amyloid quantitation with florbetapir standardized uptake value ratios to the Centiloid scale. Alzheimers Dement 14:1565-1571.

Nordberg A (2004) PET imaging of amyloid in Alzheimer's disease. lancet Neurol 3:519-527.

Ossenkoppele R, Jansen WJ, Rabinovici GD, Knol DL, van der Flier WM, van Berckel BNM, Scheltens P, Visser PJ, Verfaillie SCJ, Zwan MD, Adriaanse SM, Lammertsma AA, Barkhof F, Jagust WJ, Miller BL, Rosen HJ, Landau SM, Villemagne VL, Rowe CC, et al. (2015) Prevalence of amyloid PET positivity in dementia syndromes: a meta-analysis. JAMA 313:1939-1950.

Ossenkoppele R, Schonhaut DR, Schöll M, Lockhart SN, Ayakta N, Baker SL, O’Neil JP, Janabi M, Lazaris A, Cantwell A, Vogel J, Santos M, Miller ZA, Bettcher BM, Vossel KA, Kramer JH, Gorno-Tempini ML, Miller BL, Jagust WJ, Rabinovici GD (2016) Tau PET patterns mirror clinical and neuroanatomical variability in Alzheimer's disease. Brain 139:1551-1567.

Pontecorvo MJ, Devous MD, Kennedy I, Navitsky M, Lu M, Galante N, Salloway S, Doraiswamy PM, Southekal S, Arora AK, McGeehan A, Lim NC, Xiong H, Truocchio SP, Joshi AD, Shcherbinin S, Teske B, Fleisher AS, Mintun MA (2019) A multicentre longitudinal study of flortaucipir 
(18F) in normal ageing, mild cognitive impairment and Alzheimer's disease dementia. Brain 142:1723-1735.

Pooler AM, Polydoro M, Maury EA, Nicholls SB, Reddy SM, Wegmann S, William C, Saqran L, Cagsal-Getkin O, Pitstick R, Beier DR, Carlson GA, Spires-Jones TL, Hyman BT (2015) Amyloid accelerates tau propagation and toxicity in a model of early Alzheimer's disease. Acta Neuropathol Commun 3:14.

Price JC, Klunk WE, Lopresti BJ, Lu X, Hoge JA, Ziolko SK, Holt DP, Meltzer CC, DeKosky ST, Mathis CA (2005) Kinetic modeling of amyloid binding in humans using PET imaging and Pittsburgh compound-B. J Cereb Blood Flow Metab 25:1528-1547.

Price JL, McKeel DW, Buckles VD, Roe CM, Xiong C, Grundman M, Hansen LA, Petersen RC, Parisi JE, Dickson DW, Smith CD, Davis DG, Schmitt FA, Markesbery WR, Kaye J, Kurlan R, Hulette C, Kurland BF, Higdon R, Kukull W, et al. (2009) Neuropathology of nondemented aging: presumptive evidence for preclinical Alzheimer disease. Neurobiol Aging 30:1026-1036.

Ranganath C, Ritchey M (2012) Two cortical systems for memory-guided behaviour. Nat Rev Neurosci 13:713-726.

Reagh ZM, Ho HD, Leal SL, Noche JA, Chun A, Murray EA, Yassa MA (2016) Greater loss of object than spatial mnemonic discrimination in aged adults. Hippocampus 26:417-422.

Reitan RM, Wolfson D (1985) The Halstead-Reitan neuropsychological test battery: theory and clinical interpretation. Tuscon: Neuropsychology Press.

Rousset OG, Ma Y, Evans AC (1998) Correction for partial volume effects in PET: principle and validation. J Nucl Med 39:904-911.

Schöll M, Maass A (2020) Does early cognitive decline require the presence of both tau and amyloid- $\beta$ ? Brain 143:10-13.

Schöll M, Lockhart SN, Schonhaut DR, O'Neil JP, Janabi M, Ossenkoppele R, Baker SL, Vogel JW, Faria J, Schwimmer HD, Rabinovici GD, Jagust WJ (2016) PET imaging of tau deposition in the aging human brain. Neuron 89:971-982.

Schöll M, Maass A, Mattsson N, Ashton NJ, Blennow K, Zetterberg H, Jagust W (2019) Biomarkers for tau pathology. Mol Cell Neurosci 97:18-33.

Schröder TN, Haak KV, Jimenez NIZ, Beckmann CF, Doeller CF (2015) Functional topography of the human entorhinal cortex. Elife 4:e06738.

Schultz H, Sommer T, Peters J (2012) Direct evidence for domain-sensitive functional subregions in human entorhinal cortex. J Neurosci 32:47164723.

Shimada H, Kitamura S, Shinotoh H, Endo H, Niwa F, Hirano S, Kimura Y, Zhang M-R, Kuwabara S, Suhara T, Higuchi M (2017) Association between $\mathrm{A} \beta$ and tau accumulations and their influence on clinical features in aging and Alzheimer's disease spectrum brains: a [11C] PBB3PET study. Alzheimers Dement (Amst) 6:11-20.
Smith A (1982) Symbol digit modalities test-revised. Los Angeles: West Psychol Serv.

Sonnen JA, Santa Cruz K, Hemmy LS, Woltjer R, Leverenz JB, Montine KS, Jack CR, Kaye J, Lim K, Larson EB, White L, Montine TJ (2011) Ecology of the aging human brain. Arch Neurol 68:1049-1056.

Sperling RA, Mormino EC, Schultz AP, Betensky RA, Papp KV, Amariglio RE, Hanseeuw BJ, Buckley R, Chhatwal J, Hedden T, Marshall GA, Quiroz YT, Donovan NJ, Jackson J, Gatchel JR, Rabin JS, Jacobs H, Yang HS, Properzi M, Kirn DR, et al. (2019) The impact of amyloid-beta and tau on prospective cognitive decline in older individuals. Ann Neurol $85: 181-193$

Stroop JR (1938) Factors affecting speed in serial verbal reactions. Psychol Monogr 50:38-48.

Sun N, Mormino EC, Chen J, Sabuncu MR, Yeo BTT, Initiative AND; Alzheimer's Disease Neuroimaging Initiative (2019) Multi-modal latent factor exploration of atrophy, cognitive and tau heterogeneity in Alzheimer's disease. Neuroimage 201:116043.

Teylan M, Mock C, Gauthreaux K, Chen YC, Chan KCG, Hassenstab J, Besser LM, Kukull WA, Crary JF (2020) Cognitive trajectory in mild cognitive impairment due to primary age-related tauopathy. Brain 143:611621.

Villeneuve S, Rabinovici GD, Cohn-Sheehy BI, Madison C, Ayakta N, Ghosh PM, La Joie R, Arthur-Bentil SK, Vogel JW, Marks SM, Lehmann M, Rosen HJ, Reed B, Olichney J, Boxer AL, Miller BL, Borys E, Jin LW, Huang EJ, Grinberg LT, et al. (2015) Existing Pittsburgh compound-B positron emission tomography thresholds are too high: statistical and pathological evaluation. Brain 138:2020-2033.

Visser D, Wolters EE, Verfaillie SCJ, Coomans EM, Timmers T, Tuncel H, Reimand J, Boellaard R, Windhorst AD, Scheltens P (2020) Tau pathology and relative cerebral blood flow are independently associated with cognition in Alzheimer's disease. Eur J Nucl Med Mol Imaging 47:31653175.

Wechsler D (1997) WAIS-III, Wechsler adult intelligence scale: administration and scoring manual. San Antonio: Psychological Corporation.

Wei K, Tran T, Chu K, Borzage MT, Braskie MN, Harrington MG, King KS (2019) White matter hypointensities and hyperintensities have equivalent correlations with age and CSF $\beta$-amyloid in the nondemented elderly. Brain Behav 9:e01457.

Weigand AJ, Bangen KJ, Thomas KR, Delano-Wood L, Gilbert PE, Brickman AM, Bondi MW; Alzheimer's Disease Neuroimaging Initiative (2020) Is tau in the absence of amyloid on the Alzheimer's continuum?: a study of discordant PET positivity. Brain Commun 2:fcz046.

Ziontz J, Bilgel M, Shafer AT, Moghekar A, Elkins W, Helphrey J, Gomez G, June D, McDonald MA, Dannals RF, Azad BB, Ferrucci L, Wong DF, Resnick SM (2019) Tau pathology in cognitively normal older adults. Alzheimers Dement (Amst) 11:637-645. 